Validation of the Multidimensional Scale of Perceived Social Support (MSPSS) for family caregivers of people with dementia

*Dr Anna V. Cartwright ${ }^{\text {a }}$ https://orcid.org/0000-0002-8014-6901

Dr Richard D. Pione ${ }^{z}$ https://orcid.org/0000-0002-3195-8145

Dr Charlotte R. Stoner ${ }^{\mathrm{a}}$ https://orcid.org/0000-0002-1536-4347

Professor Aimee Spector ${ }^{\mathrm{a}}$ https://orcid.org/0000-0003-4448-8143

${ }^{a}$ Research Department of Clinical, Educational and Health Psychology, University College London (UCL), 1-19 Torrington Place, London, United Kingdom, WC1E 7HB

*Corresponding author a.cartwright.17@ucl.ac.uk 


\title{
Validation of the Multidimensional Scale of Perceived Social Support (MSPSS) for family caregivers of people with dementia
}

\begin{abstract}
Background and Objectives: The Multidimensional Scale of Perceived Social Support (MSPSS) is a measure of perceived adequacy of social support. Whilst this is an important area of research for family caregivers of people with dementia, it is not clear whether the MSPSS retains its psychometric properties when used with this population. The aim was to conduct an in-depth psychometric analysis of the MSPSS to ensure that it remains a psychometrically robust measure for this population.
\end{abstract}

Research Design and Methods: Participants completed measures online using a selfcomplete procedure. A subsample completed the MSPSS twice, within a 4-week period. Properties assessed were internal consistency, floor and ceiling effects, test-retest reliability, convergent validity and factor structure.

Results: 270 participants completed the study and 58 comprised the test-retest sample. Internal consistency was excellent for the total score $(\alpha=0.92)$ and three subscales $(\alpha=$ 0.92-0.94). Significant correlations were observed in the expected directions between depression $(\mathrm{r}=-.48, \mathrm{p}<.001)$ and mental $(r=0.32, p<.001)$ and physical $(r=0.17, p=.003)$ health-related quality of life. Test re-test reliability was excellent for the total score (ICC = $0.9095 \% \mathrm{CI}=0.84,0.94)$ and subscale scores $(\mathrm{ICC}=0.84-0.89)$. Confirmatory factor analysis indicated acceptable fit indices for the three-factor solution.

Discussion and Implications: The MSPSS has robust psychometric properties when used with caregivers of people with dementia and may be recommended for use with this population. Further research is required to establish responsiveness and determine crosscultural validity.

Keywords: dementia and cognitive disorders, social support, caregiving 


\section{Introduction}

Caring has been associated with poorer mental and physical health, including elevated levels of depression and anxiety (Schulz \& Sherwood, 2008). Carers of people with dementia $(\mathrm{PwD})$ have reported greater impacts of caring in terms of mental and physical health problems compared to caregivers for people without dementia (Ory et al., 1999).

The stress/health model (Schulz \& Martire, 2004) posits that caregivers experience stress when they perceive caring demands as threatening and their coping resources as inadequate. One such resource is social support, which has been found to reduce psychological and non-psychological care burden in caregivers of people with dementia (Han et al., 2014). Interventions focused on enhancing coping resources aim to alter these appraisals and thus reduce stress. For example, following befriending and peer support interventions, family carers of PwD have described feeling emotionally supported, enabling them to cope better with difficult situations and continue to provide care (Smith et al., 2018).

However, there is considerable heterogeneity in methods used to measure social support for caregivers of PwD. Furthermore, the psychometric properties of available measures have not been rigorously assessed in this population. There is consequently a lack of 'gold standard' measure of social support for caregivers of PwD. The lack of consistency is problematic, as it prevents pooling of outcomes, making it difficult to synthesise research findings (Dam et al., 2016).

There are a variety of social support measures that have been reported to have good psychometric properties when used with other populations (Gottlieb \& Bergen, 2010). However, the psychometric properties of these scales, when used with caregivers of PwD have not been rigorously assessed. One such measure, the Social Provisions Scale (SPS; Cutrona \& Russel, 1987) has been found to have relatively poor internal consistency when 
used with carers of people with symptoms of dementia, with Cronbach's alphas ranging from $0.5-0.74$ for the 4 subscales (Stensletten et al., 2016).

Another widely used measure, the Inventory of Socially Supportive Behaviours (Barrera et al., 1981), has been used inconsistently with family caregivers of PwD. For example, some studies have used just 11 items (Gallagher-Thompson et al., 2003), or have combined items from this scale with other items (Rabinowitz et al., 2006).

Out of the currently available measures, the Multidimensional Scale of Perceived Social Support (MSPSS; Zimet et al, 1988) was considered to be most appropriate for the present study, as it has been found to be psychometrically sound when used with a range of other populations (Hardan-Khalil \& Mayo, 2015), is freely available online, is a relatively brief 12-item measure, the items are easy to understand and it is easy to administer, score and interpret.

The MSPSS was designed to measure the perceived adequacy of support from family, friends and a significant other. In the original development study of 275 university undergraduates, confirmatory factor analysis identified the three proposed subscales: 'family', 'friends' and 'significant other' (Zimet et al., 1988). Coefficient alphas for the subscales and whole scale ranged from .85 to .91 , indicating good internal reliability. Testretest reliability was also good, with values ranging from .72 to .85 . Finally, adequate construct validity was demonstrated in significant negative correlations between the MSPSS subscales and measures of anxiety and depression (Zimet et al., 1988). Zimet et al. (1990) extended these findings and demonstrated good internal reliability and factorial validity in a sample of pregnant women, adolescents and pediatric residents.

The psychometric properties of the MSPSS have been tested and validated amongst different populations, including psychiatric outpatients (Cecil et al., 1995), older adults (Stanley et al., 1998) and adolescents (Canty-Mitchell \& Zimet, 2000). Although it has not 
been validated with caregivers of PwD, the MSPSS has been used in research with this population (Charlesworth et al. 2008). For example, Orgeta et al. (2013) administered a paper version of the MSPSS to 170 caregivers of PwD and reported a Cronbach's alpha of 0.82 , thus demonstrating good internal consistency of this measure when used with this population. However, the authors only reported internal consistency and no other measures of reliability and validity. Further analysis is therefore required to determine the measure's full psychometric properties when used with caregivers of PwD.

\section{Rationale}

It is important to establish the psychometric properties of the MSPSS specifically with family caregivers of PwD, as there are important differences between these and other caregivers. For example, family caregivers of PwD report spending significantly more hours per week providing care and greater impact of care in terms of employment complications, caregiver strain, mental and physical health problems, time away from leisure, and increased family conflict compared to 'non-dementia' family carers (Ory et al., 1999). In addition, Carers UK (2014) found that $57 \%$ of carers lost contact with family or friends as a result of caring responsibilities and/or stigma surrounding dementia, leading to increased isolation and emotional distress. These factors make caring for someone with dementia particularly challenging and unique and suggest that research on social support and the impact of caregiving in other populations may not generalise to family caregivers of PwD.

\section{Aims}

The aim of the current study was therefore to determine the psychometric properties of the MSPSS in a sample of family caregivers of PwD, hopefully enabling its wider use in both clinical and research purposes. The psychometric properties assessed included internal consistency, floor and ceiling effects, test-retest reliability, convergent validity and factor structure. 
It was hypothesised that MSPSS scores would remain relatively stable at retest, with a good level of reliability and internal consistency. With regards to convergent validity, the MSPSS was hypothesised to correlate negatively with depression ( $\mathrm{Ng}$ et al., 2015) and positively with health-related quality of life (Zhang et al., 2014). Finally, it was hypothesised that the three-factor structure previously reported (Zimet et al., 1988) would be replicated in the present sample.

\section{Materials and Methods}

\section{Participants}

The researchers emailed invitations for the study to individuals who had identified themselves as a carer of someone with dementia on Join Dementia Research Network, an online service which helps match people to dementia-related research studies. Electronic adverts were emailed to UK charities and organisations including Age UK and Alzheimer's Society, who recruited participants through their internal adverts. The study was also advertised via social media.

Inclusion criteria for participants were: age 18 years or over; currently living in the UK; unpaid family carer of a person who has a diagnosis of a primary progressive dementia; capacity to provide informed consent; able to read and write in English; and able to access questionnaires online.

\section{Design}

Data for the current study was collected as part of a larger study, additionally measuring the psychometric properties of the Positive Psychology Outcome Measure (PPOM; Stoner et al., 2018) in family caregivers of PwD, the findings of which will be reported elsewhere. All measures were administered using an online self-complete procedure on Qualtrics. Ethical approval was sought from the UCL Research Ethics Committee (REC; approval: 15139/001). 


\section{Measures}

Upon completion of a consent form, participants were required to provide demographic and clinical information, including age, gender, ethnicity, marital status, work status, education level, relation to the person with dementia, whether they were living with the person for whom they cared, whether they were the primary caregiver and the duration for which they had been caring for the person with dementia. The following measures were then counterbalanced to control for order effects.

\section{The Multidimensional Scale of Perceived Social Support (MSPSS)}

The MSPSS (Zimet et al., 1988) is a 12-item self-report measure of social support, designed to measure the perceived adequacy of social support. There are three subscales, with four items per subscale: family (e.g. item 3: My family really tries to help me), friends (e.g. item 7: I can count on my friends when things go wrong) and significant other (e.g. item 2: There is a special person with whom I can share my joys and sorrows). Respondents rate each item on a 7-point scale, from 1 (very strongly disagree) to 7 (very strongly agree). The total score is calculated by summing all responses. Possible scores range from 12 to 84 , with higher scores indicating a greater level of perceived social support. Subscale scores range from 4 to 28. The MSPSS has shown good internal reliability in other populations including pregnant women, adolescents and paediatric residents $(\alpha=.84-.92$, Zimet et al., 1990). Hospital Anxiety and Depression Scale (HADS)

The HADS (Zigmond \& Snaith, 1983) is a 14-item self-report questionnaire, with 7 questions measuring anxiety and 7 measuring depression. Each item is rated from 0 to 3 with higher scores indicated higher levels of anxiety/depression. The HADS has been recommended by the European consensus guidelines for carers of PwD (Moniz-Cook et al., 2008) and is used widely in both research and clinical practice. A recent study assessing the validity and usefulness of the HADS in caregivers of PwD concluded that the depression scale can be used with this population but suggested that the HADS does not accurately measure distress 
or anxiety (Stott et al., 2017). Therefore, only the depression subscale was used in the present study. Internal consistency in this sample was good $(\alpha=0.84)$.

\section{Short Form-12 Health Survey (SF-12)}

The SF-12 (Ware et al., 1996) is a 12-item self-report questionnaire, measuring health-related quality of life, constructed using questions from the Medical Outcomes Study (MOS) 36-item Short Form Survey (SF-36). The SF-12 measures 8 concepts: physical functioning, role limitations due to physical health problems, bodily pain, general health, vitality, social functioning, role limitations due to emotional problems and mental health. Two summary scores, the mental component score (MCS) and physical component score (PCS) were calculated, using procedures recommended by the developers (Ware et al., 1995). The SF-12 has good psychometric properties (Ware et al., 1996) and has previously been used with caregivers of PwD (Charlesworth et al., 2016).

\section{Procedure}

During completion, a response was required for all questions in order to continue to the next question. The battery was initially piloted with three caregivers to check acceptability and completion time. A further pilot analysis was conducted after 30 participants had completed the battery to check for design problems (Browne, 1995).

The study consisted of one baseline assessment during which all measures were administered and one retest assessment for a subsample of participants, during which the MSPSS was re-administered. The order of measures was counterbalanced to control for order effects. For the retest, participants were emailed an invitation to complete the MSPSS again four weeks after the date of first completion, until at least 50 participants had taken part. This time frame was chosen to minimise the likelihood of practice effects, whilst also reducing the chances of significant life events occurring between completion dates.

\section{Analysis}


The range of scores on the MSPSS were plotted to determine possible skew and kurtosis. Floor and ceiling effects were assessed by examining the number of participants achieving lowest and maximum possible scores, respectively. If more than $15 \%$ of respondents achieved these sores, the floor and ceiling effects would be considered significant (Terwee et al., 2007).

Internal consistency was measured using Cronbach's alpha, which has an acceptable range of $0.95>\alpha \geq 0.7$ (George \& Mallery, 2003). Test re-test reliability for the subsample who completed the MSPSS at both time points was measured using an Intraclass Correlation Coefficient (ICC). Magnitude guidelines were adopted, with a 'good' ranging from 0.75> ICC $>0.9$ and 'excellent' ICC considered as $\geq 0.9$ (Portney \& Watkins, 2000). Convergent validity, a subtype of construct validity, was measured using a Pearson Product-Moment Correlation Coefficient (Pearson's $r$ ).

Confirmatory Factor Analysis (CFA) was used to measure construct validity and investigate whether the three-factor structure (Zimet et al., 1988) could be replicated in the present sample. Analysis was performed using SPSS Amos version 25. The chi-squared statistic was used to determine whether the data was a good fit for the three-factor model, whereby a significant chi-squared differences test indicates a bad fit. However, this test is heavily sensitive to sample size, such that a large sample can lead to a significant chi-squared statistic even with trivial differences between the sample and fitted covariance matrices. Other fit indices were therefore reported: The Comparative Fit Index (CFI) was considered acceptable if $>0.95$ and Standardised Root Mean Square Residual (SRMR) if $<0.08$. The Root Mean Square Error of Approximation (RMSEA) was considered to indicate a good model if $<0.06$ and considered an acceptable fit if between 0.06 and 0.08 . Guidelines reported by Hu and Bentler (1999) were used for the current study, although alternatives have been suggested (e.g. Schumacker, 2015). 


\section{Results}

\section{Participant Characteristics}

A total of 293 participants consented to take part in the survey of which 270 completed all required measures. A subsample of 58 participants completed the MSPSS at time 2. The total sample consisted of 93 men and 177 women, with a mean age of 60.5 years (Table 1). They were predominantly married $(69.6 \%)$ and either retired $(47.8 \%)$ or in full-time $(21.1 \%)$ or part-time (14.1\%) employment and were mostly well-educated, with $57.4 \%$ holding an undergraduate degree or over. The vast majority of participants were white British (92.2\%).

[Table 1 near here]

The most commonly cited relationship with the PwD was daughter (40.7\%; Table 2), followed by husband (21.9\%) and approximately half of participants were living with the PwD (49.6\%). Most relatives with dementia had been diagnosed with Alzheimer's disease (48.1\%) or mixed dementia $(22.6 \%)$. The demographic and clinical characteristics appeared similar for the total sample and subsample.

[Table 2 near here]

\section{Descriptive Statistics}

The full possible range of MSPSS scores from 12 to 84 was observed $(M=56.80, S D$ $=15.84$ ). Inspection of a histogram suggested that the MSPSS total score followed a relatively normal distribution (Figure 1), however statistically, the total score was significantly negatively skewed (-0.52). The kurtosis value was 0.08 . Given the robustness of parametric tests and the expected approximate normal distribution of the data in the population, parametric tests were considered appropriate. Three participants (1.1\%) scored the lowest possible score of 12 and nine (3.3\%) scored the maximum possible score of 84 . Therefore, neither floor nor ceiling effects were observed.

[Figure 1 near here] 
The 'significant other' subscale was significantly negatively skewed (-0.60) and the kurtosis value was -0.55 . Only $5.2 \%$ of participants scored the lowest possible score of 4 , however, $16.7 \%$ scored the highest score of 28 . This is above the $15 \%$ recommended by Terwee et al. (2007), thus indicating a ceiling effect for the 'significant other' subscale.

The 'family' and 'friends' subscales were significantly negatively skewed (-0.79 and 0.69 , respectively) with kurtosis values of -0.30 and 0.08 , respectively. The lowest possible score was reported by $7.8 \%$ of participants for the 'family' subscale and $3.3 \%$ for the 'friends' subscale. No participants scored the maximum possible score for the 'family' subscale and only $5.9 \%$ achieved the maximum possible score on the 'friends' subscale. Neither the floor nor ceiling effects were therefore problematic for the 'family' and 'friends' subscales.

\section{Internal Consistency}

Internal consistency was very good with $\alpha=0.92$ and not indicative of multicollinearity ( $\alpha$ $>0.95)$. No items were identified as improving the internal consistency if deleted. Internal consistency was very good for the 'significant other', 'family' and 'friends' subscales, with $\alpha$ $=0.93, \alpha=0.94$ and $\alpha=0.92$, respectively. Again, no items were identified as improving the internal consistency if deleted.

\section{Test-retest Reliability}

The number of days between the test and retest for the subsample of 58 participants ranged from 28 to 42.5 (Median $=28.52$ ), with $69 \%$ of participants completing the retest questionnaire on the $28^{\text {th }}$ day. An 'excellent' degree of consistency was found between MSPSS scores at time 1 and time $2(\mathrm{ICC}=0.90,95 \% \mathrm{CI}=0.84,0.94)$. Consistency was 'good' for the 'significant other' subscale $(\mathrm{ICC}=0.89,95 \% \mathrm{CI}=0.82,0.93)$; the 'family' subscale $(\mathrm{ICC}=0.86,95 \% \mathrm{CI}=0.77,0.91)$; and the 'friends' subscale $(\mathrm{ICC}=0.84,95 \% \mathrm{CI}=$ $0.74,0.90)$. 


\section{Convergent Validity}

Pearson's $r$ correlations were conducted, using Bonferroni adjusted alpha levels of 0.004 per test (.05/12). Non-parametric tests were performed for comparison, however, parametric tests are reported as these are more robust and differences were negligible.

The HADS depression score was significantly negatively correlated with the total MSPSS score ( $r=-0.48, p<.001)$, as well as 'significant other' $(r=-0.34, p<.001)$, 'family' $(r$ $=-0.33, p<.001)$ and 'friends' $(r=-0.45, p<.001)$ subscales, with medium effect sizes. There were two potential outliers identified on the HADS, however as excluding these and rerunning analyses made only a negligible difference, they were retained.

The total MSPSS score was significantly positively correlated with the SF-12 PCS ( $r$ $=0.17, p=.003)$ and MCS $(r=0.32, p<.001)$, with small and medium effect sizes, respectively. The 'significant other' subscale score was significantly positively correlated with the MCS ( $r=0.20, p=.001)$ but not with the PCS $(r=0.13, p>.004)$. The 'family' subscale score was significantly positively correlated with the MCS $(r=0.26, p<.001)$ but not the PCS ( $r=0.09, p>.004)$. The 'friends' subscale score was significantly positive correlated with both the MCS $(r=0.27, p<.001)$ and PCS $(r=0.19, p=.001)$.

\section{Factor Structure}

In the CFA, although the chi-squared analysis was significant, $\chi^{2}(51, N=270)=144.829, p$ $<.001$, fit indices were suggestive of an acceptable model fit $(\mathrm{CFI}=0.97, \mathrm{SRMR}=0.04$, RMSEA $=0.08$ ). All 12 items significantly loaded onto their respective factor. Standardised factor loadings ranged from 0.79 to 0.93 (Figure 2).

[Figure 2 near here]

\section{Discussion}

This study presents strong evidence that the MSPSS maintains good psychometric properties when used with family caregivers of $\mathrm{PwD}$, thus supporting its use in research and clinical 
practice. According to criteria (Terwee et al., 2007), neither floor nor ceiling effects for the total score were problematic. The highest possible score was obtained for the significant other and friends subscales but not for the family subscale. This may be due to participants providing care for a family member and thus possibly perceiving less support as coming from family. As hypothesised, internal consistency was very good, with values similar to those reported in the original development study (Zimet et al., 1988). Test-retest reliability was excellent.

Correlations with the MSPSS total score and measures of convergent validity were significant and in the expected directions. As hypothesised, there was a negative correlation between the MSPSS total score and HADS depression score and a positive correlation between the MSPSS total score and both SF-12 component scores. A CFA showed that all items significantly loaded onto their respective factors ('significant other', 'family' and 'friends'), with fit indices suggestive of an acceptable model fit for the hypothesised threefactor model (Zimet et al., 1988). The factor loadings were similar to those reported in the original development paper (Zimet et al., 1988).

\section{Implications}

To our knowledge, this is the first paper to rigorously assess the psychometric properties of a widely used measure of social support, when used with family caregivers of PwD. The findings indicate that the MSPSS is a suitable measure of social support for family caregivers of PwD. This has important implications for research as there is currently a plethora of measures of social support used within the literature. The wide range of currently used measures makes it difficult to compare and synthesise research findings, and accordingly to draw conclusions regarding the role of social support. These findings are therefore important, as to our knowledge, the MSPSS is the first measure of social support that has been 
rigorously assessed and shown to be psychometrically sound when used with family caregivers of PwD.

Furthermore, some of the other currently used measures have been found to have relatively poor reliability when used with caregivers of PwD. For example, the internal consistency of the MSPSS is superior to that reported for the SPS, which ranged from $0.5-$ 0.74 for the four subscales (Stensletten et al., 2016). It may thus be suggested that the MSPSS be used to measure social support in future research with caregivers of PwD. A more homogeneous use of measures will allow comparability across studies and enable more rigorous research regarding the role of social support.

\section{Future Research}

An important aspect of psychometric evaluation and a criterion upon which measures are evaluated, is responsiveness (Terwee et al., 2007), or the ability of a questionnaire to detect clinically important changes over time, for example as the result of an intervention. It was not possible to establish the responsiveness of the MSPSS in the current study as no intervention was administered. Further research is therefore required to determine whether the MSPSS is able to pick up change in the perceived adequacy of social support following an intervention, in order to determine whether it can be used reliably as a clinical outcome measure. Future studies should also investigate the usefulness of the MSPSS for detecting caregivers who may benefit from interventions targeting their social support needs.

\section{Limitations}

The main limitation of this study was the lack of diversity in the sample, particularly with regards to ethnicity. There were very few participants who were from Black, Asian and Minority Ethnic (BAME) groups, with the vast majority of participants being white British. Participants were also generally well-educated. It may therefore be argued that the current sample was not representative of the wider population of family caregivers. It may have been 
helpful to have further information about participants, such as the type of caregiving provided, and the amount of time spent caring.

In addition, assessing convergent validity using Pearson's r correlation coefficients indicated that the relationship between social support and the physical component of quality of life, as measured using the PCS of the SF-12, was small albeit statistically significant. Clinical significance was not determined. The possibility that there are other concepts that are more closely linked to social support for this population warrants further research.

Finally, the lack of longitudinal data precludes testing predictive validity. Therefore, it was not possible to determine whether social support predicts depression and/or quality of life over time.

\section{Conclusions}

The MSPSS has good psychometric properties when used with family caregivers of PwD. It is hoped that this will enable greater consistency in the choice of measure used in research evaluating social support in this population. The MSPSS was significantly correlated with depression and health-related quality of life, suggesting that the perceived adequacy of social support has important implications for family caregivers' psychological wellbeing. Further research is required in order to determine the responsiveness of this measure following an intervention and asses cross-cultural validity.

\section{Acknowledgements}

None

\section{Disclosure of Interest}

The authors report no conflict of interest

\section{Funding}


None

\section{References}

Barrera. M., Sandler, I. N., \& Ramsay, T. B. (1981). Preliminary development of a scale of social support: Studies on college students. American Journal of Community Psychology, 9(4), 435-447. doi: 10.1007/bf00918174 
Browne, R. H. (1995). On the use of a pilot sample for sample size determination. Statistics in Medicine, 14(17), 1933-1940. doi:10.1002/sim.4780141709

Canty-Mitchell, J., \& Zimet, G. D. (2000). Psychometric properties of the Multidimensional Scale of Perceived Social Support in urban adolescents. American Journal of Community Psychology, 28(3), 391-400. doi:10.1023/a:1005109522457

Carers UK. (2014). State of Caring Survey 2014: Carers UK.

Cecil, H., Stanley, M. A., Carrion, P. G., \& Swann, A. (1995). Psychometric properties of the MSPSS and NOS in psychiatric outpatients. Journal of Clinical Psychology, 51(5), 593-602. doi:10.1023/A:1005109522457

Charlesworth, G., Burnell, K., Crellin, N., Hoare, Z., Hoe, J., Knapp, M....Orrell, M. (2016). Peer support and reminiscence therapy for people with dementia and their family carers: A factorial pragmatic randomised trial. Journal of Neurology, Neurosurgery \& Psychiatry, 87, 1218-1228.

Charlesworth, G., Shepstone, L., Wilson, E., Reynolds, S., Mugford, M., Price, D.... Poland, F. (2008). Befriending carers of people with dementia: randomised controlled trial. BMJ, 336(7656), 1295-1297. doi:10.1136/bmj.39549.548831.AE

Cutrona, C. E., \& Russell, D. W. (1987). The provisions of social relationships and adaptation to stress. In W.H. Jones \& D. Perlman (Eds., Advances in Personal Relationships. Greenwich, CT: JAI Press

Dam, A. E., de Vugt, M. E., Klinkenberg, I. P., Verhey, F. R., \& van Boxtel, M. P. (2016). A systematic review of social support interventions for caregivers of people with dementia: Are they doing what they promise? Maturitas, 85, 117-130. doi:10.1016/j.maturitas.2015.12.008

Gallagher-Thompson, D., Coon, D. W., Solano, N., Ambler, C., Rabinowitz, Y., \& Thompson, L. W. (2003). Change in indices of distress among Latino and Anglo female caregivers of elderly relatives with dementia: site-specific results from the REACH 
national collaborative study. Gerontologist, 43(4), 580-591.

\section{doi:10.1093/geront/43.4.580}

George, D., \& Mallery, P. (2003). SPSS for Windows step by step: A simple guide and reference. 11.0 update (4th ed. ed.). Boston: Allyn \& Bacon.

Gotleib, B. H., \& Bergen, A. E. (2010). Social support concepts and measures. Journal of Psychosomatic Research, 69(5), 511-520. doi:10.1016/j.jpsychores.2009.10.001

Han, J.W., Jeong, H., Park, J.Y., Kim, T.H., Lee, D.Y., Lee, D.W....Kim, K.W. (2014). Effects of social supports on burden in caregivers of people with dementia, International Psychogeriatrics, $26(10), 1639-1648$.

Hardan-Khalil, K., \& Mayo, A. M. (2015). Psychometric Properties of the Multidimensional Scale of Perceived Social Support. Clinical Nurse Specialist, 29(5), 258-261. doi:10.1097/nur.0000000000000148

Hu, L. t., \& Bentler, P. M. (1999). Cutoff criteria for fit indexes in covariance structure analysis: Conventional criteria versus new alternatives. Structural Equation Modeling: A Multidisciplinary Journal, 6(1), 1-55. doi:10.1080/10705519909540118

Kiecolt-Glaser, J. K., Dura, J. R., Speicher, C. E., Trask, O. J., \& Glaser, R. (1991). Spousal caregivers of dementia victims: longitudinal changes in immunity and health. Psychosomatic Medicine, 53(4), 345-362. doi:10.1097/00006842-199107000-00001

King, A. C., Oka, R. K., \& Young, D. R. (1994). Ambulatory blood pressure and heart rate responses to the stress of work and caregiving in older women. Journal of Gerontology, 49(6), M239-245. doi:10.1093/geronj/49.6.m239

Moniz-Cook, E., Vernooij-Dassen, M., Woods, R., Verhey, F., Chattat, R., De Vugt, M., .. . Orrell, M. (2008). A European consensus on outcome measures for psychosocial intervention research in dementia care. Aging \& Mental Health, 12(1), 14-29. doi:10.1080/13607860801919850 
Ng, C. G., Mohamed, S., See, M. H., Harun, F., Dahlui, M., Sulaiman, A. H., . . Taib, N. A. (2015). Anxiety, depression, perceived social support and quality of life in Malaysian breast cancer patients: a 1-year prospective study. Health Qual Life Outcomes, 13, 205. doi:10.1186/s12955-015-0401-7

Orgeta, V., Sterzo, E. L., \& Orrell, M. (2013). Assessing mental well-being in family carers of people with dementia using the Warwick-Edinburgh Mental Well-Being Scale. International Psychogeriatrics, 25(9), 1443-1451. doi:10.1017/S1041610213000835

Ory, M. G., Hoffman, R. R., 3rd, Yee, J. L., Tennstedt, S., \& Schulz, R. (1999). Prevalence and impact of caregiving: a detailed comparison between dementia and nondementia caregivers. Gerontologist, 39(2), 177-185. doi:10.1093/geront/39.2.177

Portney, L. G., \& Watkins, M. P. (2000). Foundations of Clinical Research: Applications to Practice. Upper Saddle River, NJ: Prentice Hall.

Rabinowitz, Y. G., Mausbach, B. T., Coon, D. W., Depp, C., Thompson, L. W., \& GallagherThompson, D. (2006). The Moderating Effect of Self-Efficacy on Intervention Response in Women Family Caregivers of Older Adults With Dementia. The American Journal of Geriatric Psychiatry, 14(8), 642-649.

\section{doi:10.1097/01.JGP.0000192496.73673.e5}

Schulz, R., \& Martire, L. M. (2004). Family caregiving of persons with dementia: prevalence, health effects, and support strategies. American Journal of Geriatric Psychiatry, $12(3), 240-249$.

Schulz, R., Newsom, J., Mittelmark, M., Burton, L., Hirsch, C., \& Jackson, S. (1997). Health effects of caregiving: the caregiver health effects study: an ancillary study of the Cardiovascular Health Study. Annals of Behavioral Medicine, 19(2), 110-116. doi: $10.1007 /$ bf02883327 
Schulz, R., \& Sherwood, P. R. (2008). Physical and mental health effects of family

caregiving. The American Journal of Nursing, 108(9 Suppl), 23-27. doi:10.1097/01.NAJ.0000336406.45248.4c

Schumacker, R. E. (2015). Using R with Multivariate Statistics. Thousand Oaks, CA: Sage Publications.

Smith, R., Drennan, V., Mackenzie, A., \& Greenwood, N. (2018). The impact of befriending and peer support on family carer of people living with dementia: A mixed methods study. Archives of Geroltology and Geriatrics, 76, 188-195. doi:10.1016/j.archger.2018.03.005

Stanley, M. A., Beck, J. G., \& Zebb, B. J. (1998). Psychometric properties of the MSPSS in older adults. Aging \& Mental Health, 2(3), 186-193. doi:10.1080/13607869856669

Stensletten, K., Bruvik, F., Espehaug, B., \& Drageset, J. (2016). Burden of care, social support, and sense of coherence in elderly caregivers living with individuals with symptoms of dementia. Dementia, 15(6), 1422-1435. doi:10.1177/1471301214563319

Stoner, C. R., Orrell, M., \& Spector, A. (2018). The Positive Psychology Outcome Measure (PPOM) for people with dementia: Psychometric properties and factor structure. Archives of Gerontology and Geriatrics, 76, 182-187. doi:10.1016/j.archger.2018.03.001

Stott, J., Orrell, M., \& Charlesworth, G. (2017). Validity and Usefulness of the Hospital Anxiety and Depression Scale in Carers of People with Dementia: Evidence from Confirmatory Factor Analysis, Concurrent Validity, and Measurement Invariance in a Large Sample. American Journal of Geriatric Psychiatry, 25(11), 1270-1280. doi:10.1016/j.jagp.2017.05.017

Terwee, C. B., Bot, S. D., de Boer, M. R., van der Windt, D. A., Knol, D. L., Dekker, J., .. . de Vet, H. C. (2007). Quality criteria were proposed for measurement properties of 
health status questionnaires. Journal of Clinical Epidemiology, 60(1), 34-42. doi:10.1016/j.jclinepi.2006.03.012

Ware, J., Jr., Kosinski, M., \& Keller, S. D. (1996). A 12-Item Short-Form Health Survey: construction of scales and preliminary tests of reliability and validity. Medical Care, 34(3), 220-233. doi:10.1097/00005650-199603000-00003

Ware, J. E., Kosinski, M., \& Keller, S. D. (1995). SF-12: How to Score the SF-12 Physical and Mental Health Summary Scales (Second Edition ed.). Boston, MA: The Health Institute, New England Medical Center.

Zhang, S., Zhang, S., Edwards, H., Yates, P., Li, C., \& Guo, Q. (2014). Self-Efficacy Partially Mediates between Social Support and Health-Related Quality of Life in Family Caregivers for Dementia Patients in Shanghai. Dementia and Geriatric Cognitive Disorders, 37(1-2), 34-44. doi:10.1159/000351865

Zigmond, A. S., \& Snaith, R. P. (1983). The hospital anxiety and depression scale. Acta Psychiatrica Scandinavica, 67(6), 361-370. doi:10.1111/j.1600-0447.1983.tb09716.x

Zimet, G. D., Dahlem, N. W., Zimet, S. G., \& Farley, G. K. (1988). The Multidimensional Scale of Perceived Social Support. Journal of Personality Assessment, 52(1), 30-41. doi:10.1207/s15327752jpa5201_2

Zimet, G. D., Powell, S. S., Farley, G. K., Werkman, S., \& Berkoff, K. A. (1990). Psychometric characteristics of the Multidimensional Scale of Perceived Social Support. Journal of Personality Assessment, 55(3-4), 610-617. doi:10.1080/00223891.1990.9674095 
Table 1. Participant demographics

\begin{tabular}{|c|c|c|}
\hline & $\begin{array}{l}\text { Total Sample } \\
(\mathrm{n}=270)\end{array}$ & $\begin{array}{l}\text { Test-retest } \\
\text { subsample } \\
(n=58)\end{array}$ \\
\hline \multicolumn{3}{|l|}{ Gender $n(\%)$} \\
\hline Male & $93(34.4)$ & $19(32.8)$ \\
\hline Female & $177(65.6)$ & $39(67.2)$ \\
\hline Age $M(S D)$ Range & $\begin{array}{l}60.5(14.40) 20- \\
92\end{array}$ & $\begin{array}{l}62.9(10.6) 41- \\
91\end{array}$ \\
\hline \multicolumn{3}{|l|}{ Ethnicity $n(\%)$} \\
\hline White (British) & $249(92.2)$ & $54(93.1)$ \\
\hline White (other) & $13(4.8)$ & $2(3.4)$ \\
\hline Black & $2(0.7)$ & $1(1.7)$ \\
\hline Asian & $2(0.7)$ & $0(0.0)$ \\
\hline Mixed & $3(1.1)$ & $0(0.0)$ \\
\hline Other & $1(0.4)$ & $1(1.7)$ \\
\hline \multicolumn{3}{|l|}{ Marital Status $n(\%)$} \\
\hline Single & $33(12.2)$ & $5(8.6)$ \\
\hline In a relationship & $30(11.1)$ & $2(3.4)$ \\
\hline Married & $188(69.6)$ & $44(75.9)$ \\
\hline Divorced & $10(3.7)$ & $3(5.2)$ \\
\hline Widowed & $3(1.1)$ & $1(1.7)$ \\
\hline Separated & $3(1.1)$ & $1(1.7)$ \\
\hline Other & $3(1.1)$ & $2(3.4)$ \\
\hline \multicolumn{3}{|l|}{ Employment Status $n(\%)$} \\
\hline Full-time employment & $57(21.1)$ & $9(15.5)$ \\
\hline Part-time employment & $38(14.1)$ & $15(25.9)$ \\
\hline Self-employed & $16(5.9)$ & $2(3.4)$ \\
\hline Unemployed & $13(4.8)$ & $3(5.2)$ \\
\hline Homemaker & $15(5.6)$ & $5(8.6)$ \\
\hline Student & $2(0.7)$ & $0(0.0)$ \\
\hline Retired & $129(47.8)$ & $24(41.4)$ \\
\hline \multicolumn{3}{|l|}{ Education $n(\%)$} \\
\hline Postgraduate degree (or equivalent) & $73(27.0)$ & $14(24.1)$ \\
\hline University degree (or equivalent) & $82(30.4)$ & $18(31.0)$ \\
\hline Higher education (or equivalent) & $44(16.3)$ & $11(19.0)$ \\
\hline A level (or equivalent) & $27(10.0)$ & $3(5.2)$ \\
\hline GCSE grades $\mathrm{A}^{*}-\mathrm{C}$ (or equivalent) & $24(8.9)$ & $7(12.1)$ \\
\hline Other qualifications & $9(3.3)$ & $3(5.2)$ \\
\hline No qualifications & $11(4.1)$ & $2(3.4)$ \\
\hline
\end{tabular}


Table 2. Characteristics relating to person with dementia (PwD)

\begin{tabular}{|c|c|c|}
\hline & $\begin{array}{l}\text { Total Sample } \\
(\mathrm{n}=270)\end{array}$ & $\begin{array}{l}\text { Test-retest } \\
\text { subsample }(n=58)\end{array}$ \\
\hline \multicolumn{3}{|l|}{ Relationship to PwD $n(\%)$} \\
\hline Husband & $59(21.9)$ & $12(20.7)$ \\
\hline Wife & $43(15.9)$ & $9(15.5)$ \\
\hline Son & $26(9.6)$ & $7(12.1)$ \\
\hline Daughter & $110(40.7)$ & $24(41.4)$ \\
\hline Son-in-law & $5(1.9)$ & $0(0.0)$ \\
\hline Daughter-in-law & $5(1.9)$ & $2(3.4)$ \\
\hline Granddaughter & $10(3.7)$ & $0(0.0)$ \\
\hline Grandson & $1(0.4)$ & $0(0.0)$ \\
\hline Other & $11(4.1)$ & $4(6.9)$ \\
\hline \multicolumn{3}{|l|}{ Living with $\mathrm{PwD} n(\%)$} \\
\hline Yes & $134(49.6)$ & $27(46.6)$ \\
\hline No & $136(50.4)$ & $31(53.4)$ \\
\hline \multicolumn{3}{|l|}{ Primary caregiver $n(\%)$} \\
\hline Yes & $174(64.4)$ & $37(63.8)$ \\
\hline No & $86(31.9)$ & $2(3.4)$ \\
\hline Joint primary & $10(3.7)$ & $19(32.8)$ \\
\hline \multicolumn{3}{|l|}{ Diagnosis of PwD $n(\%)$} \\
\hline Alzheimer's disease & $130(48.1)$ & $32(55.2)$ \\
\hline Vascular dementia & $33(12.2)$ & $3(5.2)$ \\
\hline Dementia with lewy bodies & $6(2.2)$ & $1(1.7)$ \\
\hline Parkinson's dementia & $5(1.9)$ & $3(5.2)$ \\
\hline Frontotemporal dementia & $13(4.8)$ & $3(5.2)$ \\
\hline Mixed dementia & $61(22.6)$ & $12(20.7)$ \\
\hline Dementia (subtype unknown) & $134.8)$ & $1(1.7)$ \\
\hline Other & $9(3.3)$ & $0(0.0)$ \\
\hline \multicolumn{3}{|l|}{ Time since diagnosis $n(\%)$} \\
\hline $0-1$ year & $40(14.8)$ & $11(19.0)$ \\
\hline $1-2$ years & $55(20.4)$ & $7(12.1)$ \\
\hline $3-4$ years & $80(29.6)$ & $19(32.8)$ \\
\hline $5-8$ years & $71(26.3)$ & $13(22.4)$ \\
\hline 9 years + & $23(8.5)$ & $7(12.1)$ \\
\hline Missing & $1(0.4)$ & $1(1.7)$ \\
\hline \multicolumn{3}{|l|}{ Time caring $n(\%)$} \\
\hline 0-1 year & $16(5.9)$ & $6(10.3)$ \\
\hline $1-2$ years & $40(14.8)$ & $4(6.9)$ \\
\hline $3-4$ years & $86(31.9)$ & $21(36.2)$ \\
\hline $5-8$ years & $76(28.1)$ & $13(22.4)$ \\
\hline 9 years + & $52(19.3)$ & $14(24.1)$ \\
\hline
\end{tabular}


Figure 1. Distribution of the MSPSS

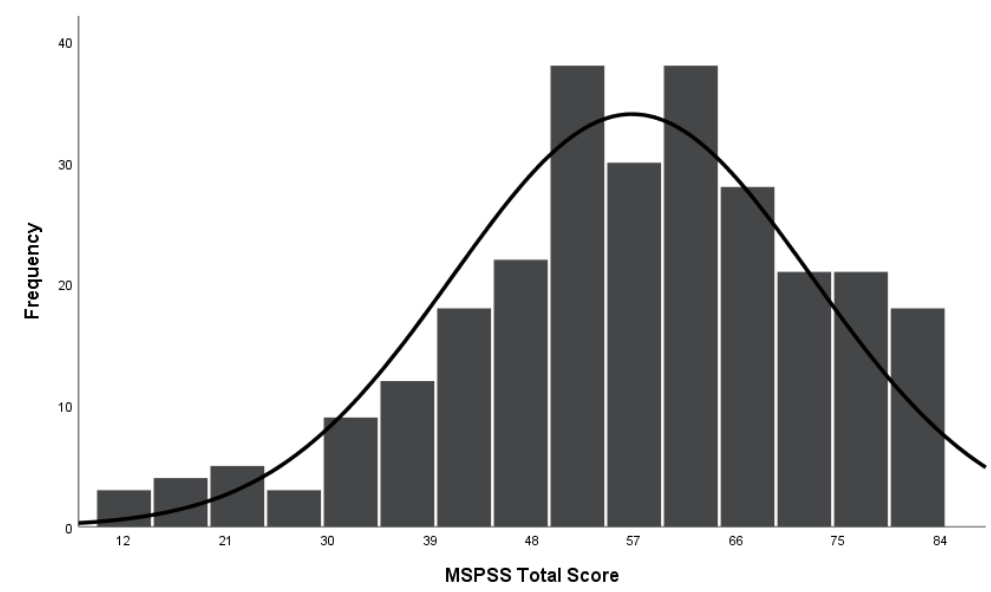


Figure 2. Factor structure of the MSPSS

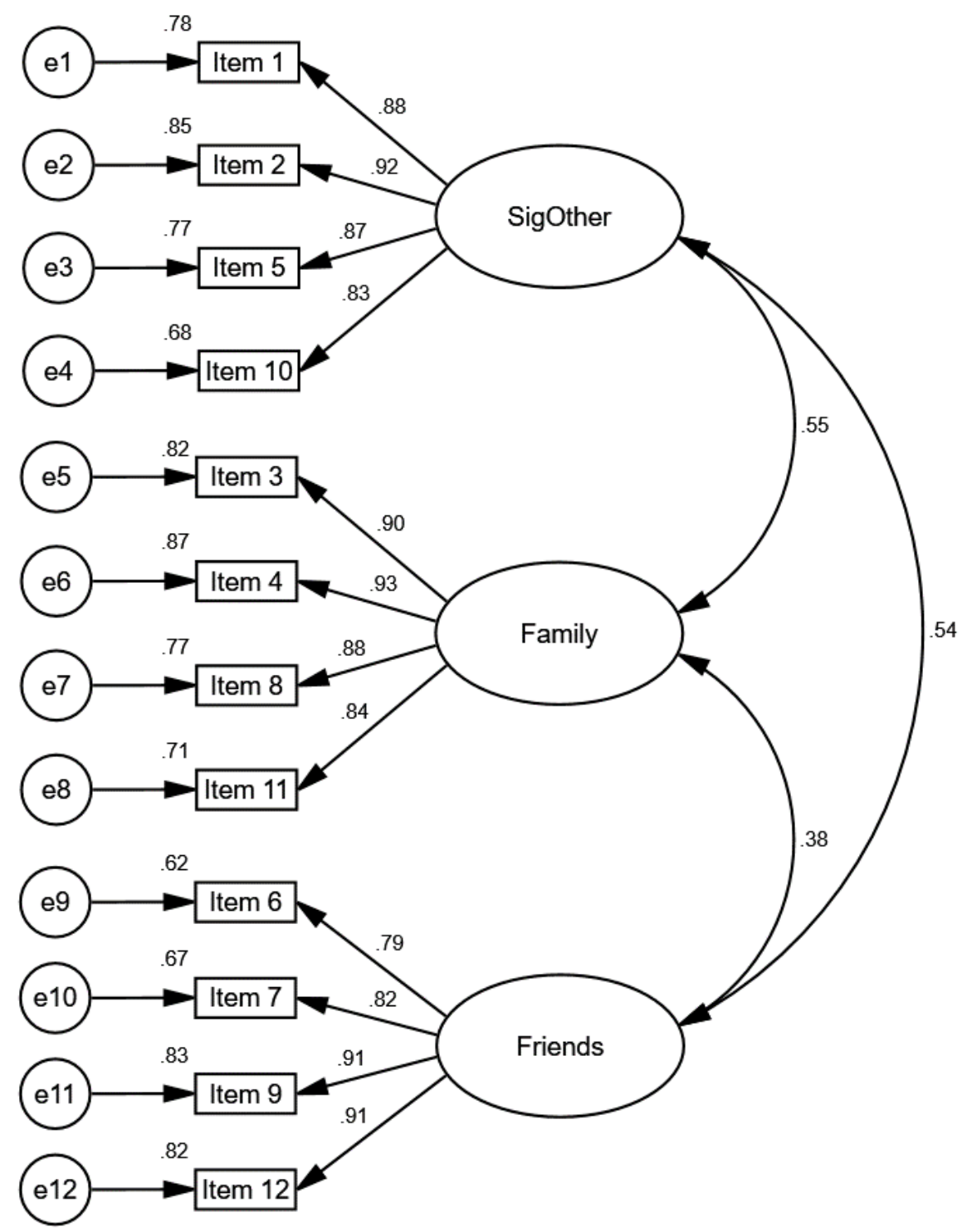

\section{Figure Captions}

Figure 1. Distribution of the MSPSS

Figure 2. Factor structure of the MSPSS 